\title{
Read Between the Walls Spatial Dimensions of the Hidden School
}

ROSSINA SHATAROVA

University of Architecture, Civil Engineering and Geodesy, Sofia 
The spatial dimension of a school transforms an abstraction into a situated phenomenon. In doing so, the context intentionally or implicitly affects education. The potential impact the physical environment and the implied connotations it carries on one's experience in and of it, is best argued by common sense. In the sense that architecture can be considered as a means to curate scenarios, anticipate and influence behaviour and even create a narrative, architecture is an agent in what composes the hidden school. In the case of educational spaces for architecture, the built environment is particularly influential as it is not only a representation of the idiosyncratic nature and program of an architecture school but also a reflection of its attitude towards the discipline and a statement about its aspirations and culture. Every aspect of an architecture school's physical presence can be interpreted as a statement about its character and spirit, despite the fact that those analyses may be inconclusive hypotheticals. A school's location and context can be related to both its self-awareness and its attitude towards the outside world.

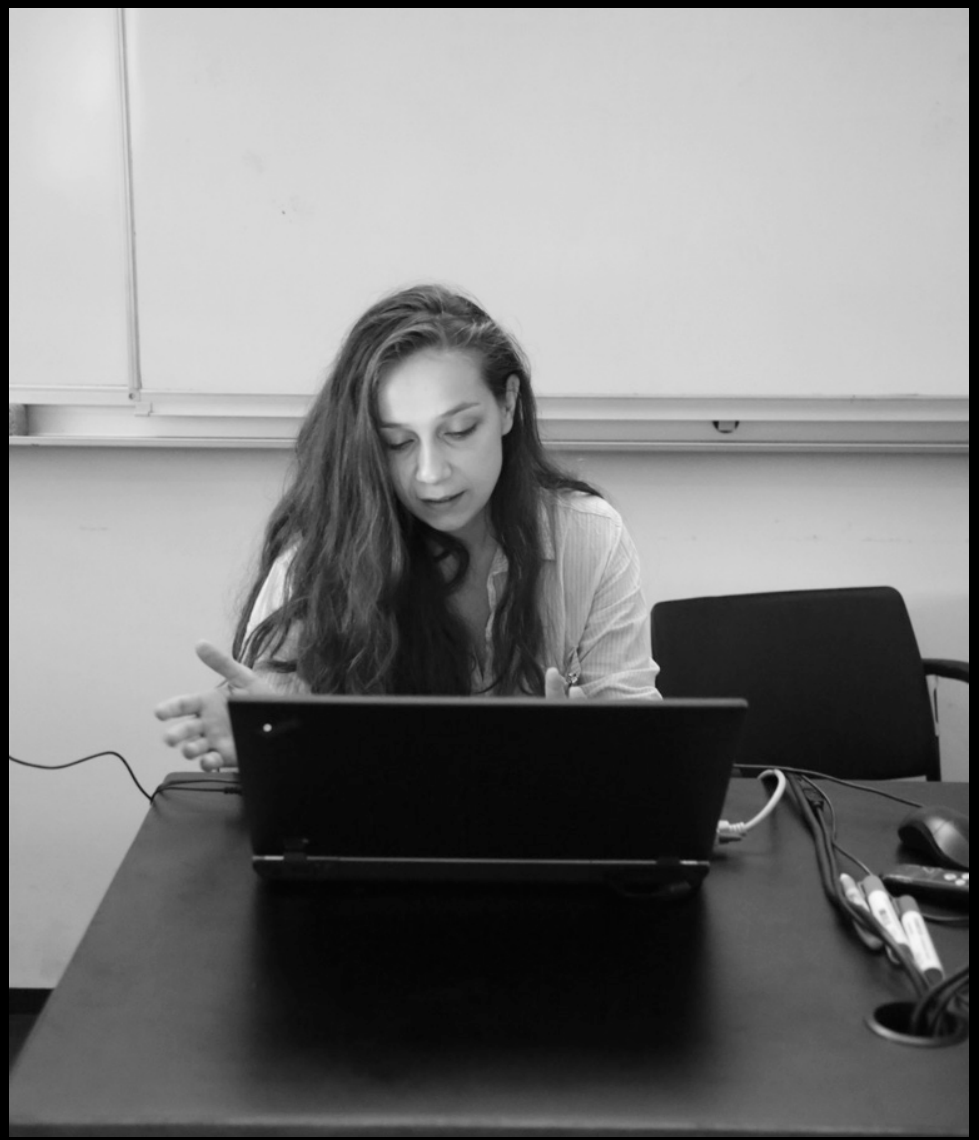




\section{INTRODUCTION}

Education cannot be confined by the walls of an institution. Any environment has the potential of being a learning environment. The famous image of Louis Kahn in conversation with students, sitting on a meadow, listening to him talk, is the ultimate proof. That is as evident in Kahn's own words. "I think of school as an environment of spaces where it is good to learn. Schools began with a man under a tree, who did not know he was a teacher, discussing his realization with a few who did not know they were students... the existence-will of school was there even before the circumstances of a man under a tree" (Kahn, 1961, p.148).

So where does that leave architecture? Is the built environment a factor in the process of education and is the case of architecture schools somehow different? Referring to the last question first, a pivotal point for this text is the contestation that schools of architecture are not the norm and should be examined individually, as an exceptional phenomenon, because of a unique additional property, inherent to them - the one of a kind designer-building-user relationship. In addition, despite taking into account the general trend towards more open, flexible and collaborative learning environments, including various informal, intermediate or "third" spaces, the room required for any design-centred education still significantly differs and greatly surpasses the conventional configuration of classrooms, lecture halls and learning commons.

"Architecture schools are not typical academic buildings" (McManus, 2018, June). This is a direct reflection of the process and method of architectural education. The idiosyncratic nature of an architectural program has its spatial implications. In order for a building to meet the primal requirements for an architecture school it has to provide for a wider spectrum of spaces usually not present elsewhere. In addition to lecture halls and class rooms, administration and faculty offices, recreational and learning commons, it needs to accommodate studio spaces for individual and group work as well as storage, display areas for crits and pin ups, maker spaces: drafting or media ateliers, analogue and digital fabrication labs and craft workshop spaces, etc. Not only do schools of architecture "suit the specific needs of a school and take on the pedagogical challenge of educating students by example", writes McManus (2018), but more often than not they are considered a representation of an institution's attitude towards the discipline. This notion is visible in official school information, in the language academic and administrative staff use when referring to the space for education, as well as in project descriptions by architects themselves and the argumentation they provide for their concepts. 
Odile Decq (2016), acclaimed architect as well as director of the Confluence Institute for Innovation and Creative Strategies in Architecture in Lyon, who has on many occasions proclaimed that "The best space to teach architecture in is a simple box" (p.5), manifests this conviction in the environment of Confluence. According to its official webpage: "The spatial organization of CONFLUENCE reflects its articulated pedagogy and generates an innovative educational structure in architecture. The spaces merge pedagogical spaces, working and living spaces as well as virtual and physical experimentation laboratories. By building the school's architecture as a physical manifestation of its pedagogical diversity, students benefit from an open, diverse and collective body of knowledge. The whole structure acts as efficient research stimulating reflection, interactions, and individual initiatives."

Identification between a school's culture and its physical environment is also apparent in the Architectural Association London School of Architecture description, again published on its official webpage, categorized symbolically under "Bedford Square", the schools address: "Today the AA retains the many unusual, idiosyncratic qualities of the kinds of 'found' event spaces that generations of students and teachers have embraced as the essential character of our school. The stately Georgian rooms in Bedford Square appropriated and transformed in to L-shaped lecture halls, members' rooms, a central bar and other shared social spaces... represent a domestic, non-institutional architecture, unusual for any school, anywhere." The AA is currently undergoing an expansion as part of a masterplan strategy. Clare Wright (2017, September),

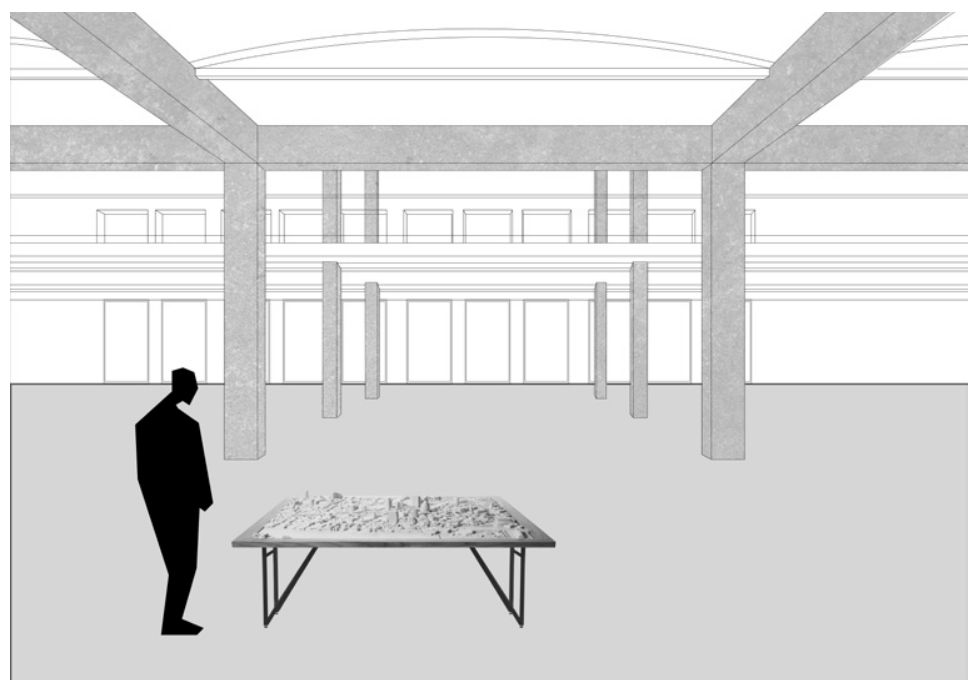

Fig. 1: A studio space at Confluence Institute School of Architecture in Lyon 
one of the cofounders of the practice of Wright \& Wright Architects, commissioned for that project, describes the school's culture though its architecture: "The Architectural Association conducts its pedagogical alchemy in a labyrinthine terrace of grand Georgian townhouses in London's Bloomsbury. Intimately intertwined with the school's sense of identity, the buildings form a responsive and still-evolving armature for activities." Former director of the AA Brett Steel also attributes educational properties to the spatial configuration of the school: "... having the bar in the middle, through which everyone passes and helping to create the sorts of informal encounter that can be just as effective as formal set-piece teaching" (Melvin, 2012, October). Attention to the bar and its décor is also paid by Peter Cook (2012, September), a distinguished academic of the Association, who depicts the lively cultured club-like atmosphere of the AA in the 60s, "which represented more than a century of elitism, arrogance, freedom but, most of all, a cosmopolitanism encouraged by the presence of an expensive chandelier and a creative use of the wine or whisky bottle or likelihood that Nervi, Bucky Fuller or Gropius might pop their head round the door".

An important note to be made here is that the remarks above concern solely the intent behind a particular design; in other words, the spaces, conditions and situations which architecture plans for and attempts at. In that sense, they are subjective. Still, the Confluence and the AA are barely the only schools of architecture where there is a relation between ethos and space. Some other examples can aid in clarifying how place, program and culture are interconnected in the case of educational spaces for architecture and reveal what the

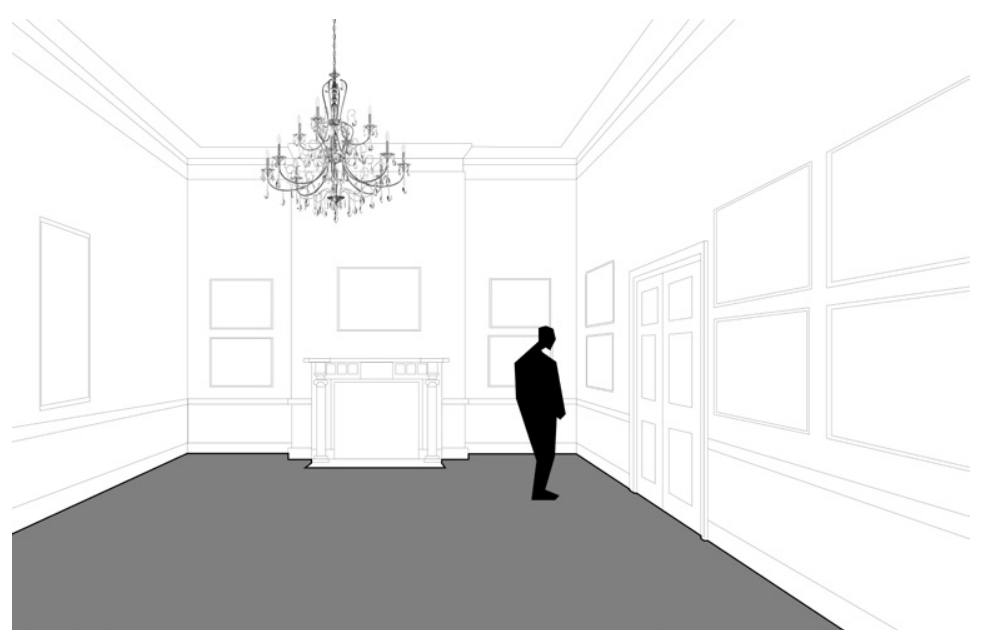


built environment hides. There are several facets of the spatial dimension to be considered.

Every aspect of an architecture school's physical presence can be interpreted as a statement about its character and spirit, despite the fact that those analyses risk being inconclusive hypotheticals. A school's location and context can be related to both its self-awareness and its attitude towards the outside world. This is applicable on all scales: from geographic position from a global perspective to the very local intermediate surrounding territory. Integration in the urban fabric, for example, suggest active involvement in the life of the city (Strelka Institute). An architecture school's situation within a campus environment, or in proximity to other faculties, can be interpreted by an effort towards stronger identification and multidisciplinarity (TU Delft). A central location implies status and speculates about an established institution (The Bartlett School of Architecture). Decentralization of a school on the other hand can be considered a statement towards a globalized world or an attempt to spread its influence via satellites (Columbia Studio X). Schools which are more introvert often seek undisturbed isolated environments far from the public gaze and retrieve to no-man-lands (Black Mountain College). The periphery is often favored by alternative or experimental educational projects (Open city). Some even explicitly choose literally underground locations as if to underline their existence on the fringe (The Public School). The practical need of more space in relation to a programs' focus on real projects is another reason for leaving the traditional schools' premises (AA Hooke Park). Change in location can also demonstrate a shift in focus and agenda (The Berlage).

Where a school is situated does indeed make a difference. However, the spatial organization of a school and the over planning concept are the main indicators of what its educational objectives and ambitions are. Collective studio spaces aim for a culture of collaboration (NTU Learning Hub). Emphasis on learning commons blur the lines between informal and formal learning (Abedian School of Architecture). A definitive statement about the importance of flexibility and reconfigurations with regard to the dynamics of architectural education is the blank enclosed space, a mere envelope to house the knowledge production within it (The Confluence). In contrast, a variety of facilities and spaces, conducive to a multifaceted process, is a mark for seeking excellence on all levels (ETH Zurich). Some schools, refraining from major changes in the curriculum, demonstrate a similar approach towards the places that host them (MARCHI). In the case of spaces reappropriated for architectural schools, the choice of a building is symptomatic. 
Some occupy architectural landmarks, despite their confined difficult to adapt or expand spaces (AA), whereas others barely need walls at all and decide on large industrial buildings with plenty of room and open space (SCl-ARC).

Despite the fact that there are many factors determining where and how a school is built, a lot about its nature can be revealed by the building and context it occupies. There is more to the setting that translates to hidden meaning. Form and volume can have a symbolic meaning as in the "Gate of Creation" (CRGS at Universidad de Monterrey). Image is among the messages that architecture conveys. Many school have opted for high profile architectural designs to serve as their emblem (Cooper Union). The desire to consolidate under one roof a fragmented school is also reason for new construction, in addition to the need for space and representation (Gerrit Rietveld Academy and The Sandberg Institute). In some cases, school edifices purposefully interpret heritage and legacy through by introducing historical building elements in the design (Qatar University). In others, the token of tradition, culture and reputation is simply a grand old tree (University of Tokyo). The vision of a school can also be declared through its engineering, efficiency or construction (UC Berkeley). Materiality and construction are another feature that is often used as a vehicle for a schools' aspirations in architecture (Carleton University School of Architecture). Even the design of the furniture within the school or the detailing can be revealing of the essence of its underlying culture (Bauhaus).

The hidden school may present itself in every aspect of a space, place and its architecture. You just have to read between the walls. "It is difficult to empirically evidence how place affects higher education, but few would disagree that the role of the buildings and landscapes that make up a university transcends function. They are part and parcel of the learning experience. Through its physical estate, a university can reinforce the high ideals of scholarship, transmit its institutional values, and nurture social bounds. The campus is one of the most valuable assets at any university's disposal" (Coulson, Roberts and Taylor, 2010, preface). Architecture schools as built structures are not just containers of human activity. They are inevitably a part of a school's identity, as well as a reflection of what often remains hidden or implicit. That is why architecture matters and the space where education takes place matters. As David Helfand (2013, June) puts it when elaborating on the idea behind the unconventional Quest University and its circular design: "We built the methodology into the concrete", placing a great emphasis on the ever present link between the environment which houses education and the pedagogy itself. 


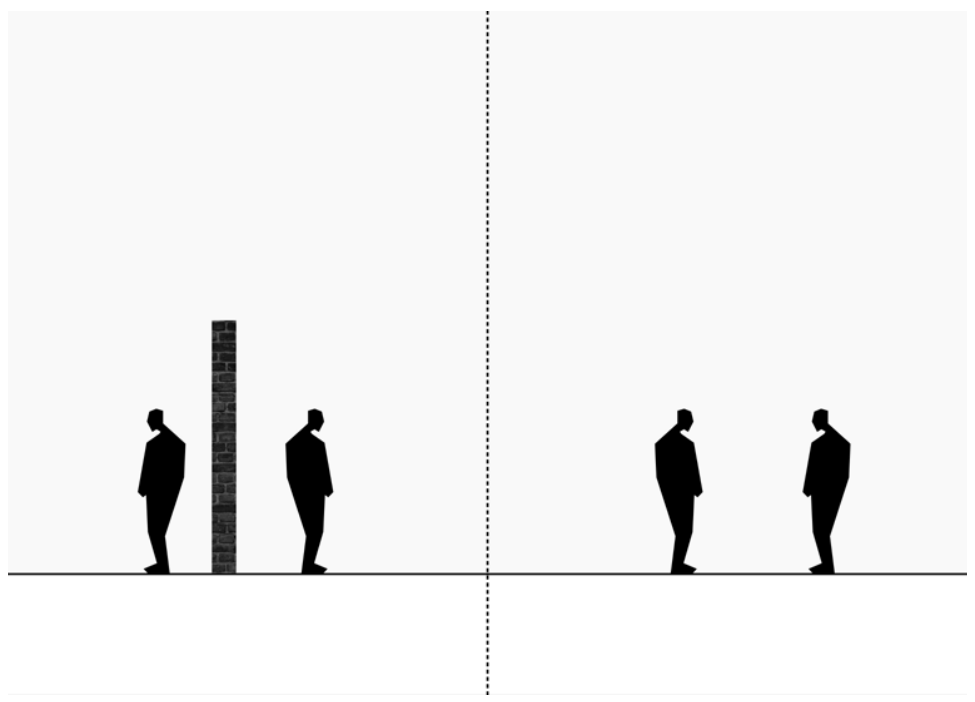

Fig. 3: An illustration of the spatial and social dimension of a wall

The spatial dimension of a school transforms an abstraction into a situated phenomenon, translating meaning through matter. In doing so, the context intentionally or subliminally affects education. The potential impact the physical environment and the implied connotations it carries on one's experience in and of it, is best argued by common sense. Consider the following example. A wall marks a boundary. Its function vary: to protect, to enclose, to constrain, to separate and differentiate between spaces, to redirect and flank. Erecting a wall, however, is an intentional design gesture. Mark Wigley (2014) often remarks that an architect designs walls at the areas of most "uncertainty" and "hesitation". That is so because the wall is a barrier or a limit. It fortifies, divides and isolates. It defines a space as an entity and provides a threshold. "The function of the traditional wall as a protective entity became visionary once it disappeared from the world... However, the fortifying architectonic wall never ceased to exist. Its trace is found... in boundaries, which perform different functions as dividers. The edge between these boundaries defines territorial limits and offers spatial definition between two different and opposing sides. The edge is a non-place - a residue of the mental separation" (Daou, Huppatz and Phuong, 2015, p.73). So be it the Berlin Wall, the notorious Tilted Arc in downtown Manhattan by Richard Serra or the screen wall between the real and artificial world in the movie The Truman Show, a wall inherently is a boundary. That associative property is translated into one's embodied experience of a physical wall. 
The existence of a wall between two entities, creates a spatial and psychological separation between them and therefore it hinders interaction to such an extent that they may not be aware of each other's presence on the opposing sides. In the alternative setup where there is no wall between two entities, several possibilities arise. There is literary room for anything to happen. The lack of a wall does not necessarily mean that the entities in question are to interact. However, what it does mean is that the act towards or against interaction is not limited by an external force. There lies the difference a single wall can make - to allow for or to reject scenarios. The example of the wall is oversimplified and seemingly reduces a complex system with both spatial and social implications to architectural determinism. Nonetheless, the purpose of the wall illustration is to demonstrate how every single composite of the built environment possess inherent potential to affect actors and actions within it: on the one hand through objective spatial properties, on the other - because of both semantics and semiotics. This suggests that architecture can be considered as a means to curate scenarios, anticipate and influence behavior and even create a narrative. In that sense, architecture is an agent and a factor in human activity, including the process of education.

Architecture does have the capacity to affect pedagogy. Yet, spatial policy is just as potent in terms of impact on education as any physical and concrete spatial tool. How the framework set by architecture is governed and appropriated on an institutional level is of upmost importance. Still, one should be reminded of the significant discrepancies, often unwritten but more often than not evident, between rules, guidelines, actual possibility and what is considered the norm in academic behavior. Referring once again to the case of the wall, policy makers are those who have the power to erect invisible walls where there are no physical ones. In a similar manner, they can create openings where they see fit. The porosity of a wall, be it a literal or a metaphorical one, is a matter of spatial policy - a significant hidden attribute of school culture. Who do you separate, how you divide, when do you isolate, why do you limit? Rethink the situation of the two entities on opposite sides of a wall in the real context of a school. Who are the two entities? Teachers and students. Administration and academic staff. Researchers and practitioners. First-year students and last-year students. Local and foreign students. School members and general public. Different sexes, different departments, different educational processes... What one is allowed and respectively prohibited within a school's walls is a matter of policy. Space allocation and utilization, opening hours, security measures, availability of access, right to use and transform the environment are all part of spatial management strategies and are within the toolkit of policy makers. 
Seemingly small acts of spatial tactics may result in great consequences (studious and social) for space users and can speak volumes about the culture and vision of an institution. According to Harvard University Graduate School of Design's spatial policy statement: "In order to guarantee that the school represents itself with a unified message... any GSD affiliate is allowed to use GSD rooms." Drew Faust (2018, April) - Harvard University's President, reasserts that "the architecture of our buildings, the spaces inside, among, and around them, and the pathways between them shape who we are as a university", as she introduces a placemaking committee, composed of faculty, students, and staff, aiming "to create new spaces that will draw our increasingly diverse and interdisciplinary community together and enhance the intellectual, social, and cultural life..." Consider the impact a joint canteen, a unisex bathroom, a 24-hour workshop, permission to hold classes outdoors, hot desks instead of offices or a collective teacher-student research space can have on the academic community, the education process, or the learning outcomes. If in coherence with each other, built architectural infrastructure and administrative management, can seamlessly foster a stimulating learning environment and induce a sense of ownership, collective responsibility and self-identification within students and faculty members.

What remains missing in the equation of architecture plus spatial policy, is the unregulated self-organized appropriation and use of school's space by students, teachers, staff and external parties. As mentioned above when illustrating both the intent behind a design project of a school and the influence of institutional tactics towards the spatial realm, the absence of a wall (an architect's decision) and unconditional access to a space (an administrator's decision), do not necessary result in the creation of a vibrant communication-conducive learning environment. If space is a prerequisite and provides a framework, policy is an amplifier and provides the hospitable condition, the true mark of a potential is how space is appropriated, experienced and enlivened by people. In this combination of factors lies the tacit essence of the school as a place.

As Jonathan Hill (2003) frames it in the forward of his book Actions of Architecture. Architects and creative users, investigating the relationship in question: "Architecture is made by use and by design" (p.1). On the one hand, a school's built environment resonates with people and has an impact on them On the other hand, the user of space reciprocate, and though this interaction, constitute a social space. Juhani Pallasmaa (2012), who has on numerous occasions written about embodied experience of space, argues: "As we enter an architectural 
space, an immediate unconscious projective identification and exchange takes place. We occupy the space and the space settles in us" (p. 54). Environmental psychology and social phenomenology reassert the relationship between the environment and its user on the basis of interdependences between person, environment and behavior, as well as a systemic view on patterns, structures and interaction models between spatial and social entities. In addition, post-occupancy evaluation reports, be their methodology often imperfect, serve as much needed concrete information on the topic (Boys, 2010) (Preiser, Nasar and Fisher, 2007). Sophisticated evidence aside, determining whether a school space "works", and understanding what it reveals about an institution, is usually not a challenge for an observer: "I enter a building, see a room, and - in the fraction of a second - have this feeling about it (Zumthor, 2006, p.13). This is not to say that outcomes of architecture and policy can always be predicted with certainty, nor that the reactions of users will be similar to one another. For sure not in the case of architecture schools (Saval, 2015, September). Stephen Holl (2002, July), in a comment related to his office practice no longer being accountable for the design of Cornell University's Milstein Hall, remarked: "Like a brain surgeon operating on his own brain, making architecture for an architecture school is a peculiarly difficult challenge. I've been involved in the process of five different architecture schools over the past 13 years and believe it is one of the most difficult architectural commissions."

The notorious example of Milstein Hall can serve as a case study for the social space of an architecture school building and how it is relatively perceived by different agents within it. After unsuccessfully working with several teams of architects, after an architectural competition whose winner did not go on to design the building, after facing serious opposition from faculty and students at Cornell Architecture Art and Planning Department, as well as some concerns from the general public, OMA and Rem Koolhaas eventually realized the building, which opened in 2011, 12 year past the initial commission. Since then the building has received some severe critique regarding several nonstructural malfunctions and failure to comply with safety regulations, while at the same time being awarded one of the highest accolades in the field by the American Institute of Architects. The response to the project and its realization has been controversial.

However, in an official statement published on the departments webpage, former deans of AAP Kent Kleinman, Gale and Ira Drukier, who have been involved in decision-making regarding the building, seem to agree that "Milstein Hall is an extraordinary new addition to AAP's suite of buildings, providing the academic and physical 'center of gravity' for 
the design arts at Cornell. Milstein Hall makes it possible for $A A P$ to radically reconfigure the way design is taught. From a pedagogical point of view, the building is transformative." Shohei Shigematsu (2011, September), partner at OMA and one of the architects responsible for the design, talks about how it exceeds the office's ambition and expectation: "to serve as a pedagogical platform for the architecture, art and planning departments - an open condition that could trigger interaction and discussion", given that according to him "students and faculty are already beginning to use the space to generate unexpected results that go beyond what we had planned." In the opinion of an objective observer - New Yorker Journalist Thomas de Monchaux (2011, November): "It's encouraging that during their first fall there, students have dubbed a favorite pin-up spot, perched at the far edge of a cantilever under the moody Ithaca sky, not a familiar architecture-school nickname borrowed from the language of incarceration, but something altogether lovelier: the Dance Floor." Last but not least, the final word of those who occupy the Milstein Hall on a daily basis - the students. The first reaction is positive as reported by Daniel Aloi's (2011, August) from the Cornell Chronicle: "I can't believe it's ours. We got the facilities that reflect the caliber of the program... Not only is this going to be our new home, but everyone has a new attitude... Everyone has this new-found sense of pride for the program." Although many of the opinions coincide, only time will tell whether students spend time on the above mentioned Dance Floor and if the place proves to be as conducive to the pedagogical vision of the institution as intended and expected. If in symbiosis, the triad formed by architectural intent, institutional spatial policy

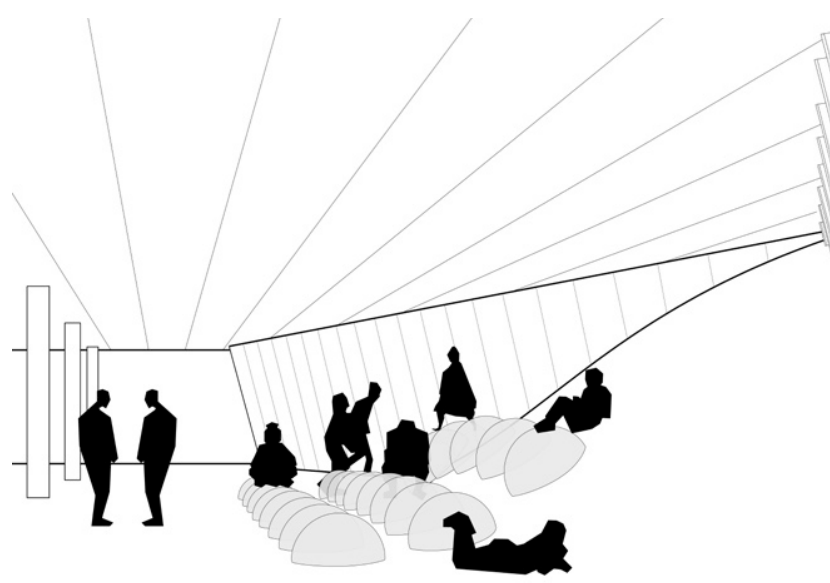

Fig. 4: The social space under the cantilever of Milstein Hall 
and self-driven spatial appropriation (not to be mistaken with Henri Lefebvre's spatial triad, though informed by it), can yield the anticipated results (Lefebvre, 1992).

And as for the walls themselves... Despite being much more than just bricks and mortar, they are far from enough. The true potential of architecture in relation to school culture lies between the walls. In his writing Architectural Manifesto, Bernard Tschumi (2012) speculates: "Architectural space will be defined by ideas as much as by real walls. Architecture will be the tension between the concept and the experience of space." This notion recognizes space "as constituted through interactions", "heterogeneous" and "always in the process of being made", meaning that any process or any being has spatial agency and can create meaning within matter (Massey, 2005, p. 9). As an architect and an actor in architectural education, I consider this understanding empowering. It is indeed the very reason why I argue that the social space of a school (the walls as well as the actions and actors within them) is instrumental to an institutions' culture. 
AA Official Webpage, Retrieved from https://www.aaschool. ac.uk/AASCHOOL/BEDFORDSQUARE/bedford.php

AAP Cornell University webpage, Retrieved from https://aap. cornell.edu/about/campuses-facilities/ithaca/milstein-hall

Aloi, D. (2011, August 29). Architecture students 'take possession' of Milstein Hall. Cornell Chronicle Online, Retrieved from http://news.cornell.edu/stories/2011/08/architecture-students-take-possession-milstein.

Boys, J. (2010). Towards Creative Learning Spaces. Re-thinking the Architecture of Post-Compulsory Education. London: Routledge.

Confluence Official Webpage. Retrieved from https://www. confluence.eu/en/campus/

Cook, P. (2012, September 28). Alvin Boyarsky (1928-1990). The Architectural Review Online, Retrieved from https:// www.architectural-review.com/essays/reputations/alvin-boyarsky-1928-1990/8636161.article.

Coulson J. \& Roberts P. \& Taylor E. (2010). University Planning and Architecture: The search for perfection. Routledge.

Daou D. \& Huppatz DJ \& Phuong Q.P. (2015). The Trace of the Wall. Limitless Boundaries. In Unbounded: On the Interior and Interiority (p. 73). Newcastle: Cambridge Scholars Publishing.

Dullea, H. N. (2002, November 7). Cornell officials and architect end design relationship. Cornell Chronicle Online, Retrieved from https://news.cornell.edu/stories/2002/07/cornell-officials-and-architect-end-design- relationship.

Griffiths, A. (2011, September 16). New OMA Building opens at Cornell University. Dezeen Online, pp. Retrieved from https:// www.dezeen.com/2011/09/16/new-oma-building-opens-atcornell-university/.

Harvard University Graduate School of Design Online Resource Centre. (n.d.). Retrieved from https://www.gsd.harvard.edu/ resources/

Heilmeyer, F. (2016). No more masters, interview with Odile Decq. Uncube Magazine (26)

Helfand, D. (2013, June 9). Designing a university for the new millennium. TEDx talk. Retrieved from https://www.youtube. $\mathrm{com} /$ watch?v=DZQe73IXZtU

Hill, J. (2003). Actions of Architecture. Architects and Creative Users. New York and London: Routledge.

Kahn, L. (1961). Form and Design. Architectural Design (31), 148. Lefebvre, H. (1992). The Production of Space. Oxford: Blackwell. Massey, D. (2005). For Space. London: SAGE Publications. 
McManus, J. (2018, 06 16). 15 Inspiring Architecture School Buildings from Around the World. Archdaily Online, pp. Retrieved from https://www.archdaily.com/896016/15-inspiring-architecture-school-buildings-from-around-the-world.

Melvin, J. (2012, October 5). Wright \& Wright's AA revamp revealed. The Architects' Journal Online, pp. Retrieved from https://www.architectsjournal.co.uk/home/wright-andwrights-aa-revamp-revealed/8636806.article.

Monchaux, T. d. (2011, November 11). Back to School. Architect Magazine Online. Retrieved from https://www.architectmagazine.com/design/back-to-school_o.

Pallasmaa, R. M. (2012). Understanding Architecture. London: Phaidon Press.

Preiser W. F. E. \& Nasar J. \& Fisher T. (2007). Designing for Designers: Lessons Learned from Schools of Architecture. Routledge.

President Faust announces committee to enhance spaces on Harvard's Cambridge campus. (2008, April 24). The Harvard Gazette Online, Retrieved from https://news.harvard.edu/ gazette/story/2008/04/president-faust-announces-committee-to-enhance-spaces-on-harvards-cambridge-campus/.

Saval, N. (10.09.2015, September 10). If you build it, they will come...won't they? New York Times, The educational Issue. Tschumi, B. (2012). Architectural Manifesto. In Architecture Concepts: Red is not a Color. New York: Rizzoli.

Wigley, M. (2014). The education of breathing. Educating Architects. How tomorrow's practitioners will learn today. London: Thames and Hudson.

Wrigh, C. (2017). Revolution and Evolution: The Architectural Association. Architectural Design, 87(5).

Zumthor, P. (2006). Atmospheres - Architectural environments-Surrounding objects. Berlin: BirkHäuser.

\section{LIST OF FIGURES:}

1 A studio space at Confluence Institute School of Architecture in Lyon

2 A room at Architectural Association London School of Architecture 3 An illustration of the spatial and social dimension of a wall 4 The social space under the cantilever of Milstein Hall 
